\title{
TOEPASSING VAN DE THEORIE VAN \\ DE VERVANGINGSWAARDE \\ BIJ LEVENSVERZEKERINGMAATSCHAPPIJEN \\ EN PENSIOENFONDSEN
}

\author{
door R. de Koning
}

\begin{abstract}
De voorbeelden aan de hand waarvan men in de bedrijfseconomische literatuur de theorie van de vervangingswaarde vindt toegelicht, zijn vrijwel zonder uitzondering ontleend aan bedrijfshuishoudingen met een goederenbeweging. De theoretische analyse blijkt zich echter geenszins tot deze bedrijfshuishoudingen te beperken en het is daarom nuttig ook eens de konsekwenties van de theorie voor andere bedrijfshuishoudingen na te gaan.

In dit artikel wil ik de betekenis van de vervangingswaardeleer voor levensverzekeringmaatschappijen en pensioenfondsen onderzoeken. Ik zal hierbij aanvangen met een theoretisch betoog. Daarna zal ik nog enige opmerkingen maken omtrent de toepassing in de praktijk.
\end{abstract}

\section{Theoretische beschouwingen.}

$\mathrm{Bij}$ de uitwerking van de theorie van de vervangingswaarde voor levensverzekeringmaatschappijen en pensioenfondsen is het doelmatig zo veel mogelijk een parallel te trekken met bedrijfshuishoudingen met een goederenbeweging. Ik ben er mij van bewust, dat deze parallel nu en dan wat geforceerd zal aandoen. Het voordeel is evenwel, dat vergelijking met hetgeen bij de uitwerking van de theorie voor bedrijfshuishoudingen met een goederenbeweging reeds gemeengoed is geworden, de analyse bij andere bedrijfshuishoudingen aanzienlijk vergemakkelijkt.

In het hierna volgende zal ik mij in eerste instantie beperken tot levensverzekeringmaatschappijen. De meeste voor deze bedrijfshuishoudingen te trekken conclusies gelden ook voor pensioenfondsen. Voor zover voor deze laatste nog bijzondere opmerkingen te maken zijn, zal ik hieraan nog afzonderlijk aandacht schenken.

De functie, welke de levensverzekeringmaatschappij in het maatschappelijk verkeer vervult, ligt in het verschaffen van bepaalde diensten (i.c. verzekeringsdiensten), waaraan in dit verkeer behoefte bestaat. Deze diensten kunnen worden opgevat als „economische goederen", welke door de maatschappij ,ten verkoop" worden aangeboden. De waarde er van kan in geld gemeten worden. De behoefte aan verzekeringsdiensten spruit voort uit de omstandigheid, dat de mens zekerheid wenst tegen de gevolgen van allerlei risico's, waaraan hij is blootgesteld. Dat deze zekerheid hem op velerlei gebied door de verzekeringmaatschappij ook geboden kan worden, is een gevolg van de werking van de wet van de grote getallen, op welke wet ik hier niet verder in behoef te gaan. De verzekeringmaatschappij biedt de gevraagde zekerheid aan de collectiviteit aan in ruil voor de individuele onzekerheden en vraagt voor deze dienst een zekere vergoeding (de premie). Bij levensverzekering gaat het hierbij om onzekerheden aangaande de omvang van financiële regelingen, indien deze omvang afhankelijk is van het tijdstip van overlijden van één of meer personen.

Het levensverzekeringscontract houdt echter nog meer in dan alleen het overnemen door een maatschappij van overlijdensrisico's. De overeenkomst wordt namelijk als regel voor vele jaren, vaak voor het gehele leven, afgesloten. De door de maatschappij bedongen vergoeding wordt dan meestal 
hetzij bij het sluiten van de overeenkomst ineens, hetzij in een aantal termijnen van de datum van sluiting af, voldaan. In het laatste geval is ook dit aantal veelal weer afhankelijk van een onzeker tijdstip van overlijden. Meestal bestaat er geen verband tussen de premie, welke in een bepaald jaar wordt betaald en de grootte van het in hetzelfde jaar door de maatschappij gelopen risico, doch dient een deel van de premies, welke in de eerste jaren verschuldigd zijn als vergoeding voor in latere jaren gelopen risico's. Uit dit alles volgt, dat een levensverzekeringscontract niet alleen het karakter heeft van een overeenkomst tot overdracht van risico, doch tevens dat van een geldverstrekking door de verzekeringnemer in het heden en terugbetaling door de maatschappij in de toekomst, dus van een crediet- of spaarovereenkomst. Hierbij zal uiteraard ook rente moeten worden verrekend.

Niet in elk contract hebben het verzekerings - en het spaarelement dezelfde betekenis. $\mathrm{Bij}_{\mathrm{ij}} \mathrm{g}$. risico-termijnverzekeringen, welke voor korte tijd, bv. een jaar - veelal in de vorm van herverzekering - worden afgesloten, overweegt het risico-element. Daarentegen speelt bij verzekering van uitgesteld pensioen en ook bij de zg. gemengde verzekering het spaarelement de belangrijkste rol.

Het is voor de analyse noodzakelijk beide kenmerken van de overeenkomst goed te onderscheiden. Ik laat nu voorlopig het spaarelement buiten beschouwing en veronderstel voorts, dat de maatschappij zonder onkosten werkt.

$B$ ij het afsluiten van een contract ruilt een maatschappij dus een door haar aangeboden verzekeringsdienst tegen de door haar bedongen vergoeding. De doelmatig gebrachte offers (onvermijdelijk, voorzienbaar en calculeerbaar), gemeten op het tijdstip van deze ruil bepalen de kostprijs van deze dienst, aldus de theorie van de vervangingswaarde. De ruilwinst is het verschil tussen de bedongen vergoeding en deze kostprijs. Voor calculatie van de te vragen vergoeding zal men zich op de aldus berekende kostprijs moeten baseren.

Om welke offers gaat het nu? Voor de beantwoording van deze vraag is een uitgangspunt te vinden in de kans, zoals die uit de statistiek, i.c. de sterftetafels, blijkt en waarin wij de werking van de wet van de grote getallen herkennen. Het begrip „,kans" moet men nu niet associëren met „,onzekerheid". Het gaat hier om verhoudingen, welke uit de sterftetafels kunnen worden afgeleid en dus calculeerbaar zijn. Op basis van de gegevens uit het contract zal men de kans in geld kunnen omrekenen. Mag de aldus verkregen uitkomst nu al zonder meer als kostprijs van de verzekeringsdienst worden opgevat? Voor een antwoord hierop is nog een nader onderzoek noodzakelijk. Hierbij is niet van belang, dat de wet van de grote getallen nooit volkomen zal werken omdat men met eindige aantallen te maken heeft. De mogelijke afwijkingen, welke hieruit kunnen voortvloeien zijn niet calculeerbaar en dus geen kostprijselement. Zo nodig kan de maatschappij het hiermede verbonden risico dekken (en dus calculeerbaar maken) door zelf van verzekeringsdiensten gebruik te maken (herverzekering).

Iets anders is echter de omstandigheid, dat de ervaring heeft geleerd, dat de overlijdenskansen in de loop der tijden geen constante grootheden zijn. Statistische gegevens hebben noodzakelijkerwijs altijd betrekking op waarnemingen uit het verleden. Een kostprijsberekening, welke zonder meer hierop wordt gebaseerd, heeft soortgelijke bezwaren als een historische kostprijscalculatie. $Z_{\mathrm{ij}}$ is alleen geoorloofd als de verwachting bestaat, dat de massa, welke aan de statistische waarneming is onderworpen, wat het waar te nemen verschijnsel betreft, onveranderlijk is. 
Voorts hebben de beschikbare sterftetafels meestal betrekking op de gehele bevolking. De groep verzekerden van een maatschappij behoeft evenwel niet representatief te zijn voor dit geheel. $Z o$ is er de invloed van de selectie, zowel uitgaande van de maatschappij als uitgaande van de verzekeringnemers en verder kan de bevolkingsgroep, waaronder de maatschappij voornamelijk werkt, van belang zijn.

Door waarnemingen onder haar eigen verzekerden kan de maatschappij op laatstgenoemde punten bruikbaarder statistieken verkrijgen, maar het is de vraag of de aldus bereikte meerdere nauwkeurigheid van enige betekenis is in vergelijking met de onzekerheid aangaande het toekomstig verloop van de overlijdenskansen in het algemeen. $\mathrm{Nu}$ tast men wat het laatste betreft ook weer niet helemaal in het duister. Het verloop van de overlijdenskansen vertoonde namelijk in het verleden een zekere lijn in die zin, dat deze kansen steeds afnamen. Door de lijn door te trekken kan men nu ook voor de levenden tot een tot op grote hoogte betrouwbare kansberekening komen. Gaat men nu een dergelijke herleide kans op basis van de gegevens uit een bepaalde levensverzekeringsovereenkomst in geld omrekenen, dan mag naar mijn mening de uitkomst als de vervangingswaarde van de betreffende verzekeringsdienst worden gekwalificeerd. Dat deze kostprijs, welke in feite uit historische gegevens is geëxtrapoleerd, toch nog slechts een ruwe benadering is, is m.i. geen bezwaar. $Z_{i j}$ is gebaseerd op de bij de beschikbare gegevens zo goed mogelijk binnen de grenzen van het calculeerbare gebrachte overlijdenskans van de verzekerde op het moment dat men de calculatie uitvoert. Ook bij andere bedrijfshuishoudingen moet men soms tot min of meer ruwe benaderingen zijn toevlucht nemen. Herleiding van uitgaafprijzen tot vervangingswaarden met behulp van indexcijfers is hier een voorbeeld van. Ondanks de bezwaren aan dergelijke herleidingen verbonden kunnen ze tot een aanvaardbaar resultaat leiden en er is soms geen andere keus. Uiteraard zal men voor de niet calculeerbare offers een open oog moeten houden, maar het niet calculeerbare karakter er van maakt deze ongeschikt voor opneming in de kostprijs. $\mathrm{Z}_{\mathrm{ij}}$ zullen gedekt moeten worden uit de winstopslag. Door regelmatig de geëxtrapoleerde overlijdenskansen te toetsen aan de daarna waargenomen sterfte zal men tot een beoordeling van de betrouwbaarheid van de extrapolatie kunnen komen.

Behalve ruilwinsten kent de theorie van de vervangingswaarde nog de $z \mathrm{~g}$. voorraadresultaten. Het gaat bij deze laatste, naar analogie met bedrijfshuishoudingen met een goederenbeweging, om de vraag of een levensverzekeringmaatschappij bij volgtijdelijke veranderingen in de vervangingswaarde van de verzekeringsdienst risico kan lopen. Dit is inderdaad het geval. Zoals wij reeds zagen worden de contracten meestal voor een lange periode afgesloten. Tijdens de duur van de overeenkomst kan blijken, dat de kansen, waarop bij afsluiting de kostprijsberekening was gebaseerd, ondanks een zo goed mogelijke benadering, in het licht van latere waarnemingen onjuist zijn geweest, m.a.w. een deel van de destijds niet te calculeren offers is later wel calculeerbaar geworden. De konsekwenties hiervan kunnen tot op zekere hoogte worden vergeleken met de gevolgen van een wijziging in de vervangingswaarde van verkøchte, doch nog niet vervangen werkeenheden van een duurzaam productiemiddel. De waarde van deze werkeenheden, welke men onder de naam ,,afschrijving" op de balans pleegt op te nemen, zal dan herzien moeten worden, waarbij het bedrag van de herwaardering als voorraadresultaat naar voren komt. Evenzo loopt de levensverzekeringmaatschappij voor elke verkochte verzekeringsdienst, tot het contract geheel is afgewikkeld, voor het nog niet afgewikkelde deel het risico van volgtijde-

m a b blz. 302 
lijke veranderingen in de vervangingswaarde van deze dienst. Manifesteert zich zulk een verandering, dan dient door herwaardering van dit niet afgewikkelde gedeelte een winst of verlies als voorraadresultaat te worden verantwoord.

Men zal wellicht opmerken, dat in het bovenstaande geen onderscheid is gemaakt tussen een aan de omvang van de bedrijfshuishouding gebonden "normale" voorraad en een met het oog op volgtijdelijke verschillen aangehouden hausse- of baissepositie. Zoals bekend betekent een stijging van de vervangingswaarde voor wat de normale voorraad betreft in de vervangingswaarde-leer geen winst, daar deze stijging onder de klem van de vervangingsverplichting ligt. Hierbij is dan stilzwijgend aangenomen, dat de normale voorraad positief is. $B$ ij een levensverzekeringmaatschappij kan echter uit hoofde van afgesloten nog niet afgewikkelde contracten alleen sprake zijn van negatieve voorraden. De afwikkeling zelf doet deze negatieve voorraden te niet gaan. Dit brengt met zich mee, dat hier niet gesproken kan worden van een voor de instandhouding van de bedrijfshuishouding in dezelfde omvang noodzakelijke vervanging van elke aan de normale voorraad onttrokken en verkochte eenheid. Men zou hier hoogstens een voor deze instandhouding noodzakelijke „verkoopplicht" kunnen onderscheiden (noodzaak om tegenover elk afgewikkeld contract een nieuw af te sluiten). $\mathrm{E}_{\mathrm{r}}$ kan dus geen sprake zijn van een mutatie in de vervangingswaarde, welke onder de klem van een vervangingsverplichting zou liggen. Naar mijn mening mag dan ook een dergelijke mutatie voor de gehele negatieve voorraad als winst of verlies worden beschouwd. In de vraag, of hierbij een normale negatieve voorraad zou kunnen worden onderscheiden naast een speculatieve, behoef $i \mathrm{k}$ mij op deze plaats dus niet te verdiepen.

Ik ga er thans toe over het spaarelement in de verzekeringsovereenkomst nader te onderzoeken. Daartoe is het noodzakelijk de verzekeringmaatschappij te beschouwen als schakel tussen twee vermogensmarkten, dus als credietinstelling. Het crediet, dat zij op haar inkoopmarkt van de verzekeringnemers opneemt, geeft $z i j$ op haar verkoopmarkt door aan vragers van crediet. $\mathrm{Z}_{\mathrm{ij}}$ zal hierbij rekening moeten houden met de termijnen gedurende welke de verzekeringnemers het crediet verstrekken. Op grond van de werking van de wet van de grote getallen mogen deze als vaste termijnen worden opgevat. Ik merk nog op, dat de verzekeringnemers, die op de verzekeringsmarkt tegenover de maatschappij als afnemers van verzekeringsdiensten optreden, bij hetzelfde contract op de vermogensmarkt juist de leveranciers van crediet voor de maatschappij zijn.

Welke rol speelt nu de theorie van de vervangingswaarde voor de levensverzekeringmaatschappij als credietinstelling? De ruil komt hier blijkbaar tot stand op het moment, dat zij een overeenkomst aangaat tot het verstrekken van crediet of een bestaand crediet van een andere vermogensverschaffer overneemt (dit laatste bv. bij belegging in effecten anders dan bij emis sie). De opbrengst bij deze ruil bestaat uit het bedongen of verwachte rendement. De vervangingswaarde wordt bepaald door de prijs, waartegen de maatschappij op hetzelfde moment crediet kan opnemen, d.i. de rentevoet, welke aan de berekening van de premies ten grondslag ligt. De ruilwinst is de contante waarde van het verschil tussen opbrengst- en vervangingsrente berekend over de gehele looptijd van de belegging.

Men zou hiertegen in kunnen brengen, dat deze winst niet voldoet aan de in de theorie van de vervangingswaarde gestelde eis van uitkeerbaarheid. Het bedrag komt immers slechts van jaar tot jaar als renteverschil ter be- 
schikking. Ik meen evenwel, dat de eis van uitkeerbaarheid moet worden opgevat als een van uiteindelijke uitkeerbaarheid. Ook bij een bedrijfshuishouding met een goederenbeweging zal de bij de ruil gemaakte winst veelal nog enige tijd vast liggen in een vordering op de afnemer en eerst na inning van deze vordering voor uitkering vatbaar zijn. Hetzelfde geldt voor de door mij bedoelde winst bij credietverstrekking, $z$ ij het dat de termijn, waarin de winst uitkeerbaar wordt, meestal heel wat langer is. Naar mijn mening is hier plaats voor het begrip „ongerealiseerde winst". Dit begrip, door de vervangingswaardetheorie terecht afgewezen, voor zover men hiermede de vermogensstijging, welke onder de klem van de vervangingsverplichting ligt zou willen aanduiden, lijkt mij doelmatig voor dat deel van de winst, dat als verschil tussen opbrengst en vervangingswaarde weliswaar echte winst is, doch nog niet in liquide vorm ter beschikking is gekomen.

Kunnen bij een levensverzekeringmaatschappij als credietinstelling naast ruilwinsten ook voorraadresultaten voorkomen? Inderdaad, want ook met betrekking tot het doorgeven van crediet kan de maatschappij risico lopen bij volgtijdelijke veranderingen in de vervangingswaarde er van. De voorraad zal hier gevonden kunnen worden uit een overzicht, hetwelk enerzijds aangeeft de aanwezige liquide middelen (exclusief hetgeen hiervan in verband met het niet synchroon verlopen van de inkomsten en uitgaven noodzakelijk in liquide vorm moet worden aangehouden), de te verwachten premies uit bestaande levensverzekeringsovereenkomsten en de te verwachten aflossingen op beleggingen; anderzijds de te verwachten uitkeringen en de gecontracteerde, doch nog niet verstrekte credieten (vóórbeleggingen). Daar vóórbelegging in de praktijk slechts voor enkele toekomstige jaren mogelijk is, althans voor een veel korter periode dan de gemiddelde duur der verzekeringscontracten, zal de ,voorraad crediet", welke uit bovenbedoeld overzicht resulteert, vrijwel altijd positief zijn. Deze voorraad zal voorts kunnen worden gesplitst in een normale aan de bedrijfsomvang gebonden positieve voorraad en een eventuele positieve of negatieve "speculatieve" voorraad.

$\mathrm{B}_{\mathrm{ij}}$ een levensverzekeringmaatschappij meet men de bedrijfsomvang af aan de grootte van de levensverzekeringportefeuille, zodat deze portefeuille ten opzichte van de bedrijfsomvang dan ook altijd ",normaal" is. Voor bovenbedoelde splitsing zal dan ook uitsluitend op de beleggingen moeten worden gelet. Daar het lopen van volgtijdelijke renterisico's niet in de eerste plaats het doel van een levensverzekeringmaatschappij is, zal zij er onder normale omstandigheden naar streven dit risico zoveel mogelijk te beperken door geen overbodige liquide middelen aan te houden en van de mogelijkheid tot vóórbelegging een maximaal gebruik te maken. Dit zal evenwel weer niet zover mogen gaan, dat het gevaar ontstaat, dat de maatschappij ter voldoening aan haar verplichtingen credieten van anderen dan de verzekeringnemers moet opnemen, hetgeen evenmin tot de normale doeleinden van de maatschappij behoort. Op grond van het bovenstaande zal de splitsing van de voorraad in een normaal te noemen gedeelte en in een hausse of baissepositie verkregen kunnen worden.

Een wijziging in de vervangingswaarde (de aan de berekening van de premies ten grondslag liggende rentevoet) betekent ten aanzien van de hausse- of baisse-positie altijd een voorraadresultaat. Het bedrag hiervan is de contante waarde van de mutatie in de vervangingsrente, berekend over de speculatieve voorraad crediet gedurende een periode gelijk aan de gemiddelde looptijd der beleggingen. Immers, had men door meer of minder te beleggen de speculatieve voorraad vermeden, dan zou de maatschappij 
voor deze gemiddelde looptijd dit voorraadresultaat ontgaan $z$ ijn.

Ten aanzien van de normale voorraad betekent een stijging van de vervangingsrente geen winst. Bij de belegging van deze voorraad zal slechts het verschil tussen de opbrengstrente en de nieuwe vervangingsrente als winst mogen worden beschouwd. Er zal dan noodzakelijkerwijs een nieuwe voorraad verkregen tegen de hogere rentevoet voor de belegde oude voorraad in de plaats zijn getreden. Het verschil tussen de oude en de nieuwe vervangingsrente zal dientengevolge nimmer te realiseren zijn en is daarom geen winst.

Daling van de vervangingswaarde betekent - geheel analoog aan hetgeen de theorie van de vervangingswaarde leert voor bedrijfshuishoudingen met een goederenbeweging - dat ook op de normale voorraad crediet een voorraadverlies wordt geleden.

Ik ben thans zover gekomen, dat ik ook de onkosten in mijn beschouwingen kan betrekken. Prijsveranderingen leveren hier geen bijzondere problemen op, welke afwijken van soortgelijke vraagstukken, welke zich bij andere bedrijfshuishoudingen voordoen. Ik zal hierop dan ook niet ingaan.

Van het totale onkostenbedrag zal men allereerst moeten afzonderen het gedeelte, dat als inefficiencyverlies of verlies door onderbezetting moet worden aangemerkt en daarom geen kostprijselement is. Budgettering van de onkosten is in verband hiermede noodzakelijk. De hiermede samenhangende vraagstukken zijn eveneens van gelijke aard als bij andere bedrijfshuishoudingen, zodat ik ook hieraan voorbij ga.

Een voor de levensverzekeringmaatschappij kenmerkend probleem vormt echter wel de verbijzondering van de kosten naar kostendragers. Een groot deel behoort namelijk tot de zg. gemeenschappelijke kosten, waarvoor zoals bekend geen theoretische oplossing van het verbijzonderingsprobleem bestaat en men slechts tot een min of meer arbitraire verdeling kan komen.

De toerekening van de onkosten na eliminering van inefficiency- en bezettingsverliezen zal in eerste instantie moeten plaats vinden naar het verzekerings- en het credietbedrijf. Tot de kosten van het credietbedrijf behoren niet alleen de kosten van de beleggingsafdeling, maar o.m. ook een deel van de kosten van het acquisitieapparaat. Immers het afsluiten van een verzekeringscontract betekent niet alleen het verkopen van een verzekeringsdienst, maar ook het aantrekken van spaargelden. Het één komt echter niet zonder het ander tot stand, zodat hier m.i. gesproken moet worden van een technische verbondenheid. De hiervoor gemaakte kosten zijn dan gemeenschappelijk. Hetzelfde geldt voor de meeste andere kostensoorten. Na een eerste verdeling over het verzekerings- en credietbedrijf dient een verdere toerekening plaats te vinden aan de calculatieobjecten (eventueel via kostenplaatsen). Als calculatieobjecten gelden het verzekeringscontract en het beleggingscontract. Binnen het verzekeringsbedrijf en het spaarbedrijf elk op zichzelf gezien doet zich het bezwaar van gemeenschappelijke kosten niet meer voor. Een theoretisch juiste verbijzondering zou dan ook verder mogelijk zijn, indien niet reeds de eerste toerekening naar beide activiteiten van de maatschappij het totaal te verbijzonderen bedrag in beide onderdelen in hoge mate arbitrair maakte. Een .,juiste" verbijzondering uitgaande van een arbitrair totaal heeft weinig zin, daar het resultaat dezelfde arbitraire elementen zal bevatten.

Tot slot van de theoretische beschouwingen nog enkele opmerkingen, welke uitsluitend voor pensioenfondsen van belang zijn. 
Er is bij een pensioenfonds sprake van een onvolkomen differentiatie ten opzichte van de verzekeringnemers, t.w. de bedrijfshuishouding of de groep van bedrijfshuishoudingen, waarmede het fonds verbonden is en de daarin werkzame arbeiders. De groep van verzekerden is als regel minder representatief voor de gehele bevolking als bij een levensverzekeringmaatschappij. Dit heeft weer konsekwenties voor de bruikbaarheid van de sterftetafels. Hier staat tegenover, dat men met selectie van de zijde van de verzekeringnemers door de verplichte toetreding geen rekening behoeft te houden. De gebondenheid aan een bepaalde groep brengt voorts met zich mee, dat als calculatieobject voor de overlijdenskansen soms de groep als geheel kan gelden. Dit leidt tot toepassing van doorsneepremies. De leeftijdsspreiding binnen de groep is dan ook een calculeerbaar kostprijselement geworden. Worden bovendien nog de premies voor een bepaalde periode gekoppeld aan de in dezelfde periode te verwachten uitkeringen, dan is er sprake van een omslagsysteem. De verzekeringsovereenkomst verliest dan haar karakter van spaarcontract. Neemt de werkgever de onkosten van het fonds voor zijn rekening, dan vervallen de hiermede samenhangende problemen. Worden alle actuariëel berekende tekorten vergoed, dan is het fonds in feite geen zelfstandige bedrijfshuishouding meer, maar geheel geintegreerd in de bedrijfshuishouding, waaraan het verbonden is.

\section{Toepassing in de praktijk.}

Van een bewuste toepassing van de theorie van de vervangingswaarde is bij levensverzekeringmaatschappijen en pensioenfondsen geen sprake. De omstandigheid echter, dat men bij de berekening van overlijdenskansen gebruik maakt van sterftetafels, welke enige jaren zijn teruggesteld, wijst wel in de richting van een min of meer onbewuste toepassing. De terugstelling kan worden opgevat als een extrapolatie van de ",historische" overlijdenskans tot de overlijdenskans van de levende. Omrekening van de premiereserve op zwaardere sterftegrondslagen kan worden gezien als een herwaardering van vroeger in aanmerking genomen overlijdenskansen. Men gaat in Nederland als regel uit van tafels voor de gehele bevolking (gesplitst naar mannen en vrouwen). De terugstelling is soms verschillend al naar gelang een vroegtijdig overlijden voor- of nadelig is voor de maatschappij. Indien dit verschil voortvloeit uit de overweging, dat de overlijdenskansen in beide gevallen verschillend zijn tengevolge van selectie is dit niet in strijd met de theorie. Het hanteren van overlijdenskansen, welke kennelijk gericht zijn op de vorming van geheime reserves, moet echter worden afgekeurd. Ik ben er mij natuurlijk van bewust, dat juist door de onzekerheid omtrent het toekomstig verloop van de sterfte een subjectief element bij de calculatie onvermijdelijk is, waarmede tevens de mogelijkheid vervalt de grens tussen geheime reserve en werkelijke verplichting objectief te bepalen. Eerst boven een bepaalde marge zal van kennelijk geheime reservering mogen worden gesproken.

$\mathrm{Z}_{\mathrm{ijn}}$ dus wat de overlijdenskansen betreft de beginselen van de vervangingswaardeleer ook bij levensverzekeringmaatschappijen en pensioenfondsen wel enigermate te herkennen, een meer bewuste toepassing verdient m.i. toch de voorkeur. Een ontwikkeling, waardoor de meer traditionele methoden niet meer aan deze beginselen zouden voldoen, wordt dan tijdig onderkend.

Voor wat de verzekeringmaatschappij als spaarinstelling betreft, ontbreekt ook een onbewuste toepassing van de theorie van de vervangingswaarde vrijwel geheel. Voor de berekening van de gehele premiereserve 
gebruikt men als regel één rentevoet, ongeacht de vraag, welke rente met de verzekeringnemers is overeengekomen. Daar het hier om contracten gaat, welke in verschillende perioden zijn gesloten, zal deze rente veelal uiteenlopen. Daar de premiereserve het verschil moet voorstellen tussen de cantante waarde van de verplichtingen tegenover de verzekeringnemers en de contante waarde van de van hen te ontvangen premies, behoort bij de berekening dezelfde rentevoet te worden aangelegd als met de contractanten is overeengekomen. Men zal dus meestal niet met één rentevoet voor alle contracten kunnen volstaan. De in de praktijk gevolgde methoden hebben het bezwaar dat de premiereserve geheime reserves gaat bevatten, waarvan de vorming en opheffing zich aan de waarneming onttrekt.

Omrekening van de premiereserve naar een hogere of lagere rentevoet kan een soortgelijk effect hebben als de door mij bedoelde boeking van ruilwinsten op "verkochte" credieten en van voorraadresultaten bij wijziging in de vervangingsrente. Dit is dan ook het doel, dat men meestal met dergelijke omrekeningen beoogt. M.i. verdient de rechtstreekse methode van boeking van deze resultaten echter de voorkeur. Meer in deze richting gaat dan ook waardering van de beleggingen op rentabiliteitswaarde op basis van de technische rentevoet. Dit blijft echter meestal toch ook een onvolkomen toepassing van de theorie van de vervangingswaarde, o.m. omdat men het systeem niet op alle beleggingen toepast en, voor zover men dit wel doet, toch niet de konsekwentie trekt om de in de rentabiliteitswaarde begrepen contante waarde van de toekomstige renteverschillen ook als winst tot uitdrukking te brengen. Als regel worden deze verschillen in een voorziening voor koersverliezen ondergebracht, welke voorziening wordt opgevat als een correctie op het waarderingssysteem, waardoor dit in feite toch weer op een lager niveau wordt getrokken.

Wat de onkosten betreft komt men meestal niet verder dan de gebruikelijke splitsing in eerste en doorlopende onkosten. Dit is echter geen verbijzondering, maar slechts het begin van een toerekening van de kosten naar de perioden, waarop ze betrekking hebben. Kosten betrekking hebbende op toekomstige perioden behoren op de balans te worden opgenomen. Berekening van de premiereserve volgens de Zillmermethode kan in beginsel hiertoe leiden. De netto-methode geeft aanleiding tot geheime reservering door afschrijving van de eerste kosten en moet dus worden afgewezen. In de praktijk wordt ook bij de Zillmermethode een deel van de eerste kosten direct afgeschreven.

Afsplitsing van inefficiencyverlies en verlies door onderbezetting uit de onkosten komt in de praktijk nooit voor.

De verbijzondering van de onkosten geschied meestal naar rato van de bedragen der overeenkomsten, dus naar draagkracht. In verband met het gemeenschappelijk karakter van de meeste onkosten acht ik deze methode geoorloofd.

I $\mathrm{k}$ ben hiermede gekomen aan het slot van mijn beschouwingen. De omvang van het onderwerp maakte slechts een globale behandeling mogelijk. Vele belangrijke deelproblemen heb ik bewust niet aangeroerd. Ik noem hier de mogelijkheid van afkoop of premievrijmaking, waardoor de duur van het verzekeringscontract minder calculeerbaar wordt dan door mij is verondersteld. Een ander probleem doet zich voor als tariefswijzigingen ook op bestaande verzekeringen van toepassing zijn. Met betrekking tot de voorraad crediet zijn de termijnen buiten beschouwing gelaten. In feite zal men echter verschillende voorraden kunnen onderscheiden, elk geldend 
voor een bepaalde toekomstige periode, bv. een voorraad voor het eerste jaar, een andere voor het tweede jaar enz. De mogelijkheid van vervroegde aflossing van verstrekte credieten heb ik evenmin in mijn beschouwingen betrokken. Dit geldt ook voor de vraagstukken, welke vast zitten aan de onzekere opbrengst bij belegging in vaste goederen en aandelen.

Afgezien van de talrijke deelproblemen hoop ik met bovenstaand artikel een bijdrage te hebben geleverd voor de popularisering van de bedrijfs economische waardetheorie bij levensverzekeringmaatschappijen en pensioenfondsen, bij welke bedrijfshuishoudingen de calculatie tot nu toe hoofdzakelijk op traditionele methoden berust. 